\title{
Impact of Inhaled Corticosteroid Treatment on 15-Year Longitudinal Respiratory Function Changes in Adult Patients with Bronchial Asthma
}

\author{
Terufumi Shimoda $^{a}$ Yasushi Obase $^{\mathrm{b}}$ Reiko Kishikawa ${ }^{\mathrm{a}}$ Tomoaki Iwanaga $^{\mathrm{a}}$ \\ ${ }^{a}$ Clinical Research Center, Fukuoka National Hospital, Fukuoka, and ${ }^{b}$ Department of Respiratory Medicine, \\ Kawasaki Medical School, Kurashiki, Japan
}

\section{Key Words}

Bronchial asthma $\cdot$ Inhaled corticosteroid $\cdot$ Lung function

\begin{abstract}
Background: Bronchial asthma is mainly controlled by inhaled corticosteroid (ICS) treatment, and discontinuation of ICS treatment can worsen asthma symptoms and reduce respiratory function. However, the longitudinal impact of ICS on lung function in adult patients is unknown. Methods: To determine whether regular ICS treatment can prevent long-term lung function deterioration in adults with bronchial asthma, we recruited 167 adult asthma patients who first visited Fukuoka National Hospital in 1995 and underwent lung function tests in 1995, 1996 and 2010. Regular ICS treatment was continued in 102 patients (regular group), while 39 patients received irregular ICS treatment (irregular group). Changes in lung function were compared retrospectively between the groups. The influences of smoking, disease severity and disease duration were also analyzed. $\boldsymbol{R e}$ sults: The forced expiratory volume in $1 \mathrm{~s}\left(\mathrm{FEV}_{1}\right)$ values increased in the regular group 1 year after the initiation of therapy, but they decreased in the irregular group. At year 15 , the predicted $\mathrm{FEV}_{1} \%$ had decreased significantly more in the irregular group than in the regular group $(p<0.05) ; \mathrm{FEV}_{1}$ decreased by $28.2 \mathrm{ml} /$ year (SD 24.5) in the regular group and
\end{abstract}

by $44.6 \mathrm{ml} /$ year $(32.5)$ in the irregular group $(\mathrm{p}<0.05)$. The decrease in $\mathrm{FEV}_{1}$ was greater in smokers than in nonsmokers, despite regular ICS treatment, and it was significantly greater in patients with severe asthma than in those with mild or intermittent disease. Delay in ICS initiation also affected the annual FEV ${ }_{1}$ decrease. Conclusions: Regular ICS, introduced early when symptoms are mild, could prevent lung function from worsening significantly. Smoking should be strongly discouraged in asthma patients.

(c) 2013 S. Karger AG, Basel

\section{Introduction}

Bronchial asthma is a chronic inflammatory disease. Since the mid-1990s, the main therapeutic strategy for the disease has been inhaled corticosteroid (ICS) treatment [1]. Regular ICS treatment can maintain a stable asthmatic status, but its discontinuation usually leads to worsening of asthma symptoms and decreased respiratory function [2]. The worsening of asthma symptoms is related to declining lung function, which results from continuous airway inflammation [3]. The commencement of ICS treatment at a very early stage of asthma can reduce the risk of a later decline in lung function [4]. Regular ICS treatment is effective in preventing the worsening of

\section{KARGER}

E-Mail karger@karger.com

www.karger.com/iaa
(C) 2013 S. Karger AG, Basel

$1018-2438 / 13 / 1624-0323 \$ 38.00 / 0$
Correspondence to: Dr. Terufumi Shimoda

Clinical Research Center, Fukuoka National Hospital

4-39-1 Yakatabaru, Minami-ku

Fukuoka 811-1394 (Japan)

E-Mail t-shimoda@mfukuoka2.hosp.go.jp 
symptoms, asthma-related deaths and hospitalization; this efficacy is long lasting $[5,6]$. A long-term study of adult asthma, which lasted 15 years, from 1976 to 1994 (a period before the widespread use of ICS treatment), showed that the forced expiratory volume (FEV) decreased by $38 \mathrm{ml} /$ year in asthmatics and by $22 \mathrm{ml} /$ year in non-asthmatics [7].

In a 5-year follow-up study, the number of subjects with a significant reduction in FEV in $1 \mathrm{~s}\left(\mathrm{FEV}_{1}\right)$ after 5 years was lower when ICS were used regularly, compared to intermittently, although this difference was not statistically significant [8]. A 10-year follow-up study of the effects of ICS treatment revealed that the annual decrease in the $\mathrm{FEV}_{1}$ of patients receiving ICS treatment was $25 \mathrm{ml}$ /year, compared to $51 \mathrm{ml} /$ year in patients not receiving this treatment. However, in that study, the diagnosis of asthma was self-reported, the ICS dosages and patient compliance were unknown, and the patients had not initiated ICS treatment before enrolling in the study.

We believe that ICS can affect the course of pulmonary function in asthma. In a 15-year study (1995-2010), we investigated the changes in the lung function of adult asthmatics whose diagnosis was definite, without other diseases, and who began ICS treatment for the first time once they were enrolled in the study. We also examined the influence of smoking, disease severity and disease duration on the efficacy of ICS treatment.

\section{Materials and Methods}

\section{Subjects and Study Design}

Asthmatic outpatients at our hospital (Fukuoka National Hospital, Fukuoka, Japan) undergo pulmonary function tests at the same time each year. Eight hundred and fifty-six adult asthmatic patients first visited our hospital in 1995 . Of these, 167 patients underwent lung function tests in 1995, 1996 and 2010. Of these 167 patients, 26 patients were in an exacerbation period and were not stable; their data were excluded. The remaining 141 patients had no other respiratory, heart, infectious, or other diseases [e.g., chronic obstructive pulmonary disease (COPD), pneumonia, chronic heart failure]. Regular ICS treatment was continued in 102 of the 141 patients (i.e., the regular group; they visited the hospital regularly every 4 months and demonstrated $\geq 80 \%$ adherence to the ICS treatment), whereas 39 of the 141 patients had irregular ICS treatment (i.e., the irregular group; they did not visit the hospital and did not receive ICS treatment regularly) (fig. 1). The adherence to ICS treatment in the regular group was secured by keeping an asthma diary and maintaining the prescribed dose. Changes in the results of lung function tests and the number of treatment and severity steps, determined by GINA guidelines, were compared retrospectively between the regular and irregular groups [1].

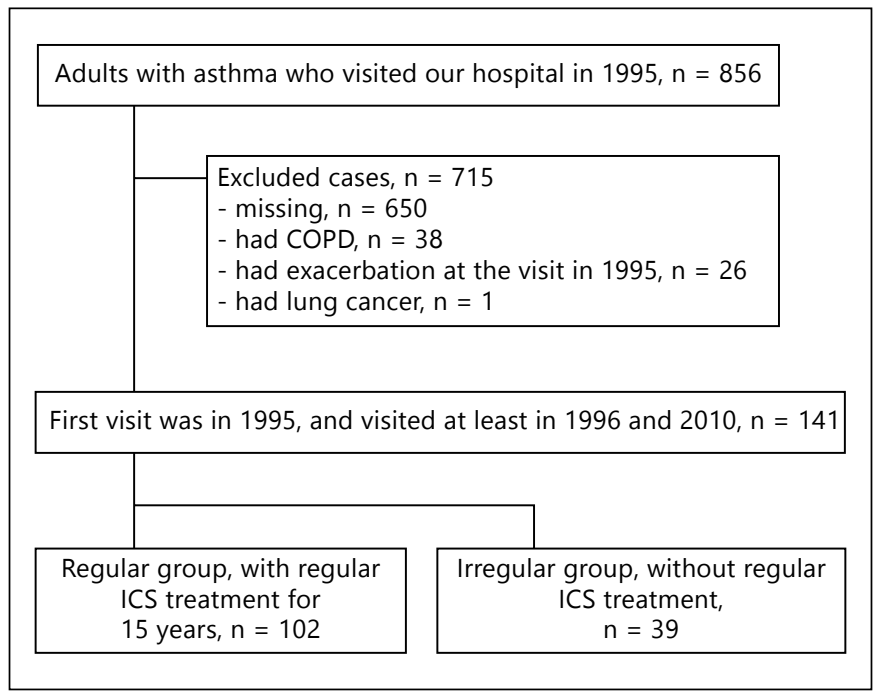

Fig. 1. Subject selection. Among 856 adult asthmatic patients who first visited Fukuoka National Hospital in 1995, 167 underwent lung function tests in 1995, 1996 and 2010, facilitating comparisons at 1 and 15 years. Of these 167 subjects, 26 were in an exacerbation period and were not stable; these patients were excluded. The remaining 141 patients had no other respiratory, heart, infectious, or other diseases. Regular ICS treatment was continued in 102 patients (regular group), while 39 patients underwent irregular ICS treatment (irregular group).

The study was approved by the Institutional Review Board of the Fukuoka National Hospital (Fukuoka, Japan; review No. 2012). The study details were put on display in the hospital without receiving written consent from the participants because the study was observational (i.e., based on medical records) and did not involve any invasive procedures.

\section{Statistical Analysis}

Using $\mathrm{t}$ tests, various factors were compared between the regular and irregular groups in 1995, 1996 and 2010. Using the statistical analysis software StatMate III (ATMS Co., Ltd., Tokyo, Japan), the relationships between the changes and background factors were analyzed by the $\chi^{2}$ test and Friedman's test. The level of significance ( $p$ value) was set at 0.05 . The data are presented as the means and SDs (in parentheses).

\section{Results}

\section{Subject Characteristics}

In 1995, the age distribution ranged from 20 to 67 years old in the regular group and from 21 to 64 years old in the irregular group. The patients in the regular group visited the hospital 8.2 times (SD 4.6) per year, and the mean dosage of the initial ICS treatment (Aldecin ${ }^{\circledR}$ or Becotide ${ }^{\circledR}$, both of which are beclomethasone inhalation 
Table 1. Patient characteristics in 1995

\begin{tabular}{|c|c|c|c|}
\hline & $\begin{array}{l}\text { ICS regular } \\
\text { treatment } \\
\text { group } \\
(\mathrm{n}=102)\end{array}$ & $\begin{array}{l}\text { ICS irregular } \\
\text { treatment } \\
\text { group } \\
(\mathrm{n}=39)\end{array}$ & $\begin{array}{l}\mathrm{p} \\
\text { value }\end{array}$ \\
\hline Age, years & $50 \pm 14$ & $51 \pm 15$ & 0.81 \\
\hline \multicolumn{4}{|l|}{ Sex } \\
\hline Male & $55(54)$ & $21(54)$ & \multirow[t]{2}{*}{0.99} \\
\hline Female & $47(46)$ & $18(46)$ & \\
\hline Body mass index, $\mathrm{kg} / \mathrm{m}^{2}$ & $22.2 \pm 3.3$ & $22.5 \pm 4.3$ & 0.80 \\
\hline \multicolumn{4}{|l|}{ Disease duration } \\
\hline$<2$ years & $72(71)$ & $29(74)$ & \multirow[t]{2}{*}{0.66} \\
\hline$\geq 2$ years & $30(29)$ & $10(26)$ & \\
\hline \multicolumn{4}{|l|}{ Disease severity } \\
\hline Mild persistent & $30(29)$ & $9(23)$ & \multirow[t]{3}{*}{0.65} \\
\hline Moderate persistent & $33(32)$ & $12(31)$ & \\
\hline Severe persistent & $39(38)$ & $18(46)$ & \\
\hline \multicolumn{4}{|l|}{ Type } \\
\hline Atopic & $83(81)$ & $28(72)$ & \multirow[t]{2}{*}{0.25} \\
\hline Non-atopic & $19(19)$ & $11(28)$ & \\
\hline \multicolumn{4}{|l|}{ Smoking status } \\
\hline Current smoker & $18(18)$ & $6(15)$ & \multirow[t]{3}{*}{0.93} \\
\hline Ex-smoker & $24(23)$ & $10(26)$ & \\
\hline Never smoked & $60(59)$ & $23(59)$ & \\
\hline ICS dosage, beclomethasone & & & \\
\hline equivalent, $\mu \mathrm{g} /$ day & $800 \pm 380$ & - & \\
\hline $\mathrm{FEV}_{1}, \%$ predicted & $78 \pm 18$ & $90 \pm 23$ & 0.03 \\
\hline
\end{tabular}

Values are presented as $\mathrm{n}(\%)$ or mean \pm SD.

treatments) was $800 \mu \mathrm{g} /$ day (380). The participants maintained asthma diaries. Their adherence to ICS treatment was nearly $100 \%$. The irregular group patients visited the hospital only 2.2 times (2.3) per year. In 1995, age, sex, body mass index, disease duration, disease severity, type (i.e., atopic or nonatopic), and smoking status were not different between the groups (table 1 ). The $\mathrm{FEV}_{1} \%$ predicted was higher in the irregular group than in the regular group $(\mathrm{p}=0.03)$.

\section{Fifteen-Year Changes in FEV}

After 1 year, the mean $\mathrm{FEV}_{1} \%$ predicted increased in the regular group [from 78 (18) to $80 \%$ (18)], but it decreased in the irregular group [from 90 (23) to 83\% (18); $\mathrm{p}<0.01]$. After 15 years, the mean FEV\% predicted decreased less in the regular group [to $74 \%(21)]$ than in the irregular group [to $71 \%(12) ; \mathrm{p}<0.05$ ]. The $\mathrm{FEV}_{1}$ decreased by $28.2 \mathrm{ml} /$ year (24.5) in the regular group and by $44.6 \mathrm{ml} /$ year $(32.5)$ in the irregular group $(\mathrm{p}<0.05)$ (fig. 2a).

Impact of Inhaled Corticosteroid on Lung Function in Asthma
Influence of Smoking Status on the Long-Term Effects of ICS Treatment in the Regular Group

In the regular ICS treatment group, the $\mathrm{FEV}_{1}$ reduction over 15 years was $41.4 \mathrm{ml} /$ year (42.5) in current smokers $(\mathrm{n}=18)$ and $22.9 \mathrm{ml} /$ year $(21.7)$ in patients who never smoked ( $n=60 ; p<0.05)$ (fig. $2 b)$. There was no significant relationship between the $\mathrm{FEV}_{1}$ reduction and the number of pack-years $(\mathrm{r}=0.33, \mathrm{p}=0.19)$.

\section{Influence of Asthma Severity on the Efficacy of ICS in} the Regular Group

We divided the regular group into 3 subgroups, based on disease severity: (1) mildly persistent $(\mathrm{n}=30)$, (2) moderately persistent $(n=33)$, and (3) severely persistent $(\mathrm{n}=39)$. The $\mathrm{FEV}_{1} \%$ predicted values increased in all of the subgroups in the first year. However, over 15 years, the values decreased in the mildly persistent, moderately persistent and severely persistent groups by 1.2 (4.8), 6.2 (9.8) and 29.4\% (29.3), respectively. The decrease rate was significantly higher in severe asthma cases than in mild asthma cases $(\mathrm{p}<0.05)$; however, the mean $\mathrm{FEV}_{1}$ decreased by 20.4 (21.8), 27.1 (32.1) and 53.9 $\mathrm{ml} /$ year (52.1) in the mildly persistent, moderately persistent and severely persistent groups, respectively, over 15 years. The intergroup differences were significant $(\mathrm{p}<$ 0.05) (fig. 2c).

\section{Influence of Disease Duration on ICS Efficacy in the \\ Regular Group}

We divided the regular group into 2 subgroups, based on disease duration: $\geq 2$ years $(\mathrm{n}=30)$, or $<2$ years $(\mathrm{n}=$ 72). After 1 year, both groups exhibited increased $\mathrm{FEV}_{1} \%$ predicted. However, the mean $\mathrm{FEV}_{1} \%$ predicted decreased by $7.4 \%(8.4)$ in patients with a long duration until ICS treatment commencement and by $3.6 \%$ (5.1) in the group with a duration of $<2$ years $(\mathrm{p}<0.05)$. $\mathrm{FEV}_{1}$ decreased over 15 years by $43.7 \mathrm{ml} /$ year (43.2) in the longduration group and by $26.3 \mathrm{ml} /$ year (31.4) in the shortduration group $(\mathrm{p}<0.05)$ (fig. $2 \mathrm{~d})$.

\section{Changes in Treatment and Symptom Steps in Each \\ Group}

Over 15 years, treatment steps 2, 3 and 4 in the regular group changed from 32 to 29 , from 24 to 33 and from 44 to $38 \%$, respectively. This finding indicated little change in the dose of ICS (equivalent, beclomethasone), although the types of ICS treatment varied [e.g., fluticasone with and without salmeterol (51 and 31 patients, respectively); budesonide with and without formoterol (10 and 5 patients, respectively)]. 

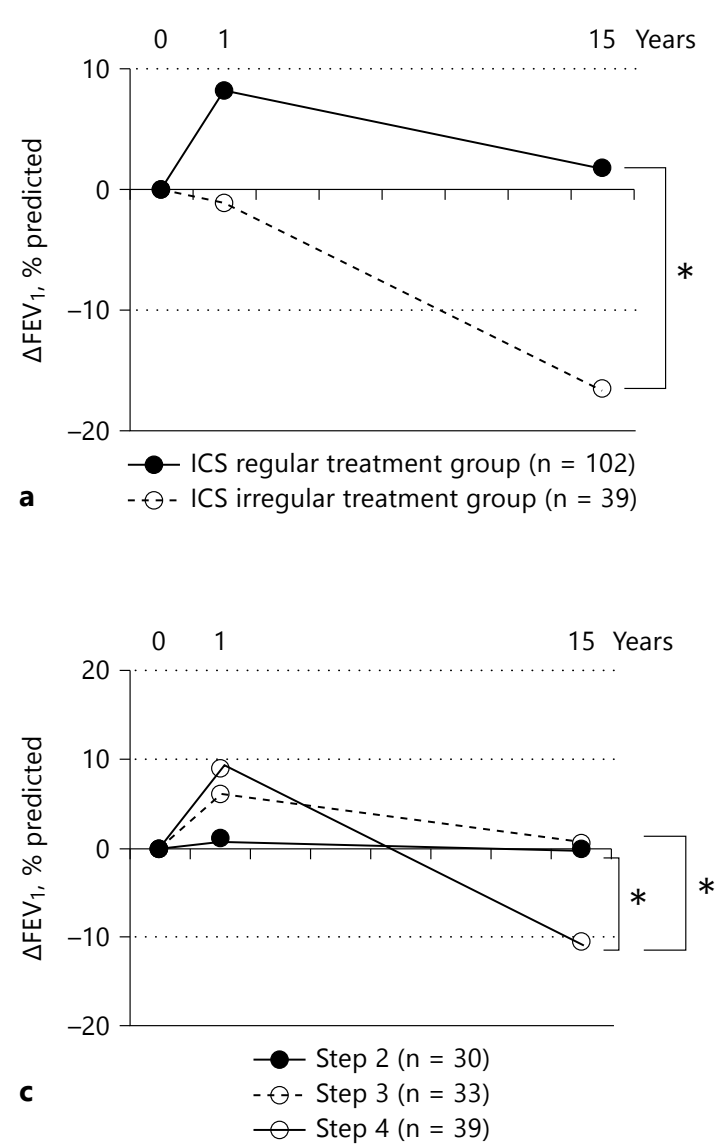

Fig. 2. a Changes in $\mathrm{FEV}_{1}$ over 15 years. The mean $\mathrm{FEV}_{1}$ increased after 1 year $[78.5(17.7)$ to $86.5 \%(28.5)]$ in the regular treatment group but decreased in the irregular treatment group [86.7 (18.8) to $85.7 \%$ (20.5); $\mathrm{p}<0.01$ ]. Moreover, over 15 years, the $\mathrm{FEV}_{1} \%$ predicted decreased more sharply in the irregular treatment group than in the regular treatment group (decrease of 16.6 vs. $6.3 \%{ }^{*} \mathrm{p}<$ $0.05)$. $\mathrm{FEV}_{1}$ decreased by $28.2 \mathrm{ml} /$ year (24.5) in the regular treatment group and by $44.6 \mathrm{ml} /$ year (32.5) in the irregular treatment group $(* \mathrm{p}<0.05)$. $\mathbf{b}$ The influence of smoking status on the longterm effects of ICS treatment. In the regular ICS treatment group, the $\mathrm{FEV}_{1}$ reductions over 15 years were $41.4 \mathrm{ml} /$ year $(42.5)$ in current smokers $(\mathrm{n}=18)$ and $22.9 \mathrm{ml} /$ year $(21.7)$ in those who never smoked $\left(n=60 ;^{*} p<0.05\right)$. c The influence of asthma severity on the efficacy of ICS treatment. We divided the regular group into 3 subgroups based on disease severity: mildly persistent $(n=30)$, moderately persistent $(n=33)$, and severely persistent $(n=39)$.

Over 15 years, the distribution in the regular group of symptom steps 1,2, 3 and 4 among the patients changed from 10, 25, 35 and 30 patients to 77, 17, 6 and 0 patients, respectively. This finding indicated that ICS treatment improved the patients' overall severity significantly $(\mathrm{p}<0.01)$ (fig. 3$)$. However, over 15 years, the
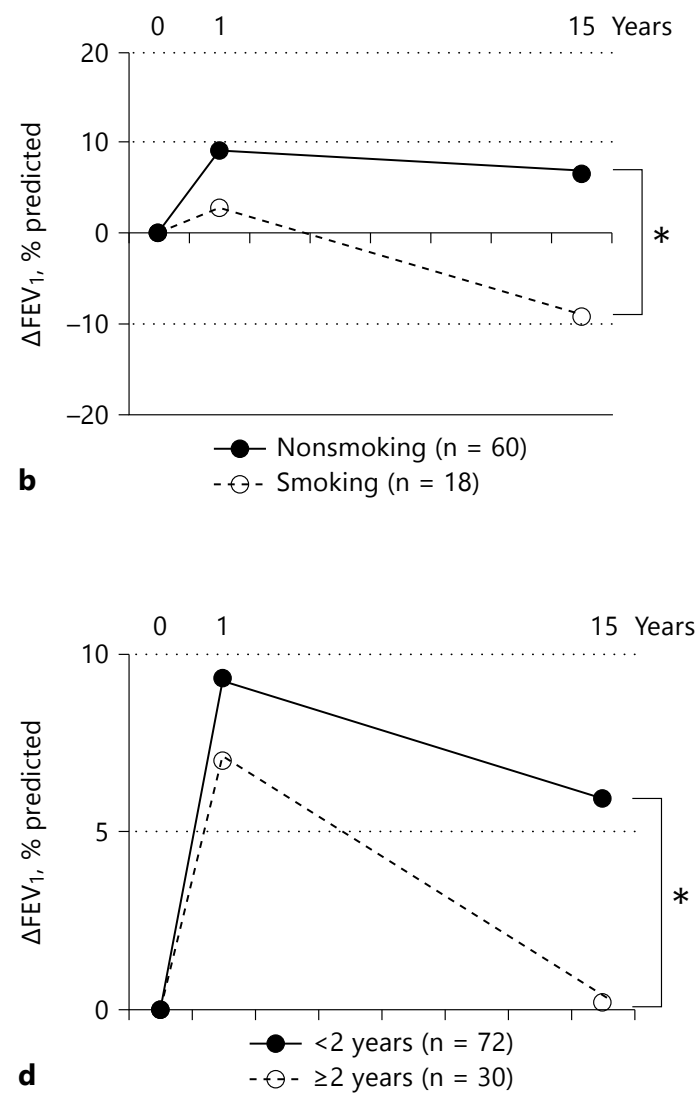

The $\mathrm{FEV}_{1} \%$ predicted values increased in all of the subgroups in the first year, but they decreased by 1.2 (4.8), 6.2 (9.8) and $29.4 \%$ (29.3), respectively, over 15 years. The decrease was significantly greater in severe than in mild cases $(* \mathrm{p}<0.05)$. Mean $\mathrm{FEV}_{1}$ decreased by 20.4 (21.8), 27.1 (32.1) and $53.9 \mathrm{ml} /$ year (52.1), respectively, in the 3 subgroups over 15 years, and the intergroup differences were significant $\left.{ }^{*} \mathrm{p}<0.05\right)$. $\mathbf{d}$ The influence of disease duration on ICS efficacy. We divided the regular treatment group into 2 subgroups on the basis of disease duration ( $\geq 2$ years, $n=30$; $<2$ years, $\mathrm{n}=72$ ). Both groups exhibited increased $\mathrm{FEV}_{1} \%$ predicted after 1 year. However, the mean $\mathrm{FEV}_{1} \%$ predicted decreased by $7.35 \%$ (8.4) in patients with longer-lasting disease and by $3.6 \%(5.1)$ in the latter group $(* p<0.05) . F^{*} V_{1}$ decreased over 15 years by $43.7 \mathrm{ml} /$ year (43.2) in patients with longer-lasting disease and by $26.3 \mathrm{ml} /$ year (31.4) in the shorter-duration group $(* \mathrm{p}<0.05)$.

distribution in the irregular group of steps 1,2, 3 and 4 among the patients was $0,13,36$ and 51 patients, indicating a worsening of severity. The number of exacerbations in the regular group was 6.7 (6.9) over 15 years, but the number of exacerbations in the irregular group was unknown. 


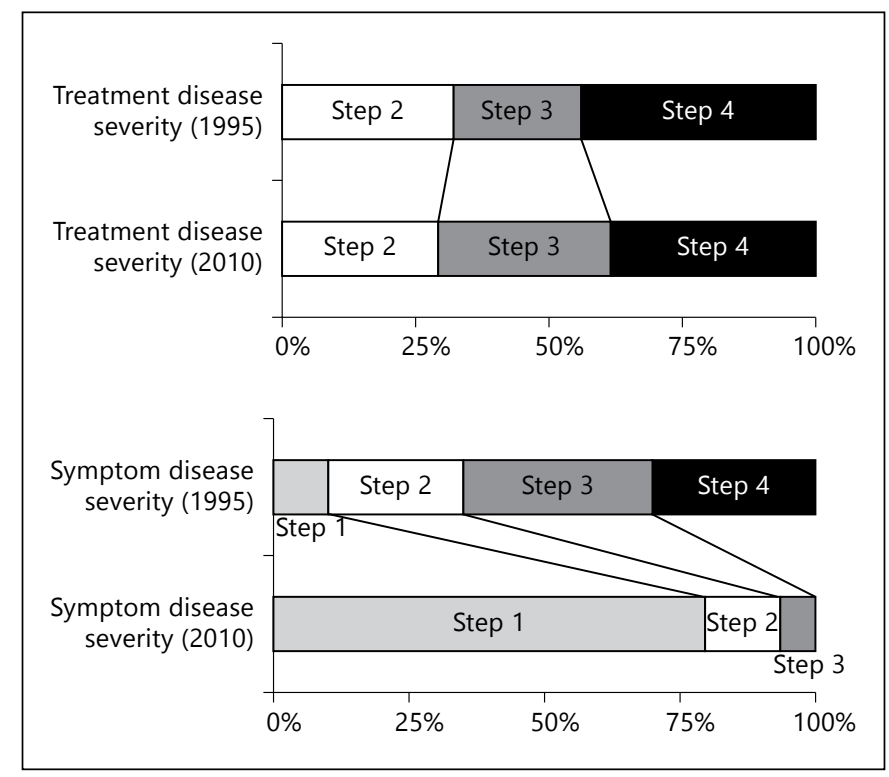

Fig. 3. Changes in treatment and symptom steps. Treatment steps in the regular treatment group (steps 2/3/4) changed from 32/24/44 to $29 / 33 / 38 \%$, respectively, over 15 years, showing a proportional reduction at step 4 . The symptom steps (steps $1 / 2 / 3 / 4$ ) changed over 15 years, from $10 / 25 / 35 / 30$ to $77 / 17 / 6 / 0$, respectively, in the regular treatment group, showing that ICS had improved the overall severity significantly $(\mathrm{p}<0.01)$.

Other Influences on Longitudinal Changes in FEV

In the regular group, the patients' age, sex, body mass index, $\mathrm{FEV}_{1} \%$, and atopic status did not cause changes in $\mathrm{FEV}_{1} \%$ predicted (data not shown).

\section{Discussion}

In this 15 -year retrospective, longitudinal follow-up study of adults with well-diagnosed asthma, we found that regular ICS treatment ameliorated the course of the disease, but insufficient treatment could not suppress a decrease in pulmonary function. We also found that smoking, disease severity and a delay in starting ICS treatment worsened the longitudinal efficacy of ICS treatment.

The present survey covered the years 1995-2010, which was a period after ICS treatment became popular. As the oldest report, Lindgren et al. [9] showed the longterm effects of beclomethasone treatment on the oral steroid-dependent bronchial asthma for 1 year in 1977. The $\mathrm{FEV}_{1}$ of regular ICS users significantly increased after 1 year, but it decreased by $28 \mathrm{ml} /$ year over 15 years. However, the $\mathrm{FEV}_{1}$ of irregular ICS users decreased by $45 \mathrm{ml} /$ year over 15 years.

Impact of Inhaled Corticosteroid on Lung Function in Asthma
In a 15-year survey (1976-1994), Lange et al. [7] documented $\mathrm{FEV}_{1}$ decreases of 38 and $22 \mathrm{ml} /$ year in study participants with and without asthma, respectively. In a 10year follow-up study, Lange et al. [10] proved that the annual decrease in FEV was reduced by approximately $15-20 \mathrm{ml} /$ year in asthmatics who received ICS. These studies suggest that the ability of ICS prevention to decrease $\mathrm{FEV}_{1}$ was approximately 10-17 ml/year.

We emphasize that the patients in the regular group in our study included only asthmatics without COPD who demonstrated good adherence to ICS treatment. All of the patients began beclomethasone treatment for the first time on entry into the study in 1995. At the first visit, the patients in the irregular group had a normal or higher lung function than those in the regular group; however, after 15 years, the irregular group's lung function decreased to a level lower than that of the regular group. In contrast, regular inhalation treatment prevented a large decrease in $\mathrm{FEV}_{1}$. Regular ICS treatment changed the disease symptoms (e.g., severity) (fig. 3). However, we could not determine the factors that were associated with the changes. Therefore, we must investigate this issue in a further study.

These results indicate the importance of continuous ICS treatment for a long period to maintain lung function in asthma patients. Frequent exacerbations can decrease $\mathrm{FEV}_{1}$ [3]. In our study, 6.7 exacerbations occurred over 15 years in the regular group, but unfortunately, we did not confirm the exacerbations in the irregular group. Because damage to lung function begins at the onset of asthma, its pathological progression might be prevented through early and long-term ICS treatment.

We also found that smoking, disease severity and the delayed introduction of ICS treatment interfered with the efficacy of ICS treatment, even in the regular group. $\mathrm{FEV}_{1}$ decreased more in smokers than in nonsmokers (41 vs. $23 \mathrm{ml} /$ year, respectively). In a 19-year respiratory function survey examining the relationship between asthma and smoking, $\mathrm{FEV}_{1}$ was lowest in asthmatics who were heavy smokers [11]. In that study, respiratory function was more severely affected with each passing year in smoking asthmatic patients than in nonsmoking nonasthmatics. Siatkowska et al. [12] reported that dyspnea, coughing, sputum production, and wheezing were correlated with the severity of a patient's smoking habit and that measurements of lung function (e.g., $\mathrm{FEV}_{1}, \mathrm{FEV}_{1} \%$ and forced vital capacity) decreased as the amount and duration of smoking increased. A study evaluating the efficacy of corticosteroids in chronic asthmatics revealed that $\mathrm{FEV}_{1}$ improved only in nonsmokers [13]. Chalmers

Int Arch Allergy Immunol 2013;162:323-329 327 
et al. [14] reported that smoking weakened the effect of corticosteroids in mild asthma. Smoking might notably weaken the effects of corticosteroids in patients with asthma $[13,15]$.

In the current study, the decrease in $\mathrm{FEV}_{1}$ was significantly greater in patients with severe asthma $(54 \mathrm{ml} /$ year) than in patients with mild or moderate disease (20 or $27 \mathrm{ml} /$ year, respectively). We similarly found that the delayed introduction of ICS treatment affected the annual FEV decrease ( $44 \mathrm{ml} /$ year in patients with a delay of $\geq 2$ years vs. $26 \mathrm{ml} /$ year in patients with a delay of $<2$ years). Finucane et al. [16] found that decreased responsiveness to steroids was correlated with disease duration and severity in adult asthma. A 5-year follow-up study showed that a lower $\mathrm{FEV}_{1}$ was correlated with a longer duration of illness [16] and that severe asthmatics with airflow limitation (i.e., $\mathrm{FEV}_{1} \%$ predicted $<50 \%$ ) had a longer duration of illness, compared to asthmatics without airflow limitation (i.e., $\mathrm{FEV}_{1} \%$ predicted $>80 \%$ ) $[17$, 18]. Cassino et al. [19] reported that asthmatics with a long illness duration had lower lung function that did not reverse to normal levels by bronchodilator treatment. This finding is consistent with our results. The severity of asthma at the time of initiation of ICS treatment might affect the subsequent decline in respiratory function. Thus, early intervention is important for preventing a severe decline in respiratory function in adult asthma patients [2, 20-22].

The first limitation of this study is that it was performed retrospectively. However, a prospective approach would not be appropriate for this type of natural, longitudinal follow-up study. The retrospective approach is re- lated to the second limitation: the small number of the study participants. We strictly omitted patients who had any other respiratory diseases, such as COPD or lung cancer. This patient selection criterion resulted in a highquality study. The numbers of participants in the groups were 102 and 39, respectively, which was unbalanced. This problem was statistically resolved by applying nonparametric analysis. Many patients were omitted. We selected patients with good treatment adherence to keep the study reliability high. Not analyzed in the study were the changes in a patient's ICS treatment (e.g., beclomethasone - Becotide or Aldecin - to fluticasone/salmeterol, budesonide/formoterol, fluticasone, or budesonide). We believe that this change was not a problem because the treatment steps did not change over the 15 years (fig. 3).

In conclusion, ICS treatment efficacy was influenced by smoking, disease severity and the delayed introduction of ICS treatment. The early introduction of regular ICS treatment could help to prevent lung function from worsening. These findings evidently indicate that ICS treatment could change the natural course of asthma.

\section{Acknowledgments}

We thank Miss Kojima and Miss Oda for their technical assistance in undertaking this study.

\section{Disclosure Statement}

The authors have declared that they have no conflict of interest.

\section{References}

1 GINA Global Strategy for Asthma Management and Prevention. NIH Publication No 02-3659. GINA update 2010. http://www.ginasthma.org

-2 Haahtela T, Jarvinen M, Kava T, Kiviranta K, Koskinen S, Lehtonen K, Nikander K, Persson T, Selroos O, Sovijarvi A, Stenius-Aarniala B, Svahn T, Tammivaara R, Laitinen LA: Effects of reducing or discontinuing inhaled budesonide in patients with mild asthma. N Engl J Med 1994;331:700-705.

- 3 Bai TR, Vonk JM, Postma DS, Boezen HM: Severe exacerbations predict excess lung function decline in asthma. Eur Respir J 2007; 30:452-456.

4 O'Byrne PM, Pedersen S, Busse WW, Tan WC, Chen YZ, Ohlsson SV, Ullman A, Lamm CJ, Pauwels RA, START Investigators Group: Effects of early intervention with inhaled budesonide on lung function in newly diagnosed asthma. Chest 2006;129:1478-1485.

-5 Suissa S, Ernst P, Kezouh A: Regular use of inhaled corticosteroids and the long term prevention of hospitalisation from asthma. Tho$\operatorname{rax} 2002 ; 57: 880-884$.

6 6 Suissa S, Ernst P, Benayoun S, Baltzan M, Cai B: Low-dose inhaled corticosteroids and the prevention of death from asthma. N Engl J Med 2000;343:332-336.

7 Lange P, Parner J, Vestbo J, Schnohr P, Jensen G: A 15-year follow-up study of ventilatory function in adults with asthma. $\mathrm{N}$ Engl J Med 1998;339:1194-1200.

8 Boulet LP, Jobin C, Milot J, Turcotte H: Fiveyear changes in airflow obstruction and airway responsiveness in mild to moderate asthma. Clin Invest Med 1994;17:432-442.
-9 Lindgren S, Eriksson NE, Lindholm N: Experience of local inhalation of beclomethasone dipropionate (Becotide) in the treatment of adult steroid-dependent asthmatic patients. Scand J Respir Dis Supple 1977;101:163-172.

10 Lange P, Scharling H, Ulrik SC, Vestbo J: Inhaled corticosteroids and decline of lung function in community residents with asthma. Thorax 2006;61:100-104.

-11 James AL, Palmer LJ, Kicic E, Maxwell PS, Lagan SE, Ryan GF, Musk AW: Decline in lung function in the Busselton Health Study: the effects of asthma and cigarette smoking. Am J Respir Crit Care Med 2005;171:109-114.

12 Siatkowska H, Jastrzebski D, Kozielski J: Smoking and clinical manifestation, lung function impairment, resulting comorbidities. Pol Merkur Lekarski 2010;29:8-13. 
13 Chaudhur R, Livingston E, McMahon AD, Thomson L, Borland W, Thomson NC: Cigarette smoking impairs the therapeutic response to oral corticosteroids in chronic asthma. Am J Respir Crit Care Med 2003;168: 1308-1311.

14 Chalmers GW, Macleod KJ, Little SA, Thomson LJ, McSharry CP, Thomson NC: Influence of cigarette smoking on inhaled corticosteroid treatment in mild asthma. Thorax 2002;57:226-230.

15 O’Byrne PM, Lamm CJ, Busse WW, Tan WC, Pendersen S, START Investigators Group: The effects of inhaled budesonide on lung function in smokers and nonsmokers with mild persistent asthma. Chest 2009;136: 1514-1520.
6 Finucane KE, Greville HW, Brown PJ: Irreversible airflow obstruction. Evolution in asthma. Med J Aust 1985;142:602604.

17 Cibella F, Cuttitta G, Bellia V, Bucchieri S, D’Anna S, Guerrera D, Bonsignore G: Lung function decline in bronchial asthma. Chest 2002;122:1944-1948.

18 Bumbacea D, Campbell D, Nguyen L, Carr D, Barnes PJ, Robinson D, Chung KF: Parameters associated with persistent airflow obstruction in chronic severe asthma. Eur Respir J 2004;24:122-128.

19 Cassino C, Berger KI, Goldring RM, Norman RG, Kammerman S, Ciotoli C, Reibman J: Duration of asthma and physiologic outcomes in elderly nonsmokers. Am J Respir Crit Care Med 2000;162:1423-1428.
20 Overbeek SE, Kerstjens HA, Bogaard JM, Mulder PG, Postma DS, The Dutch Chronic Nonspecific Lung Disease Study Groups: Is delayed introduction of inhaled corticosteroids harmful in patients with obstructive airways disease (asthma and COPD)? The Dutch CNSLD Study Group. Chest 1996;110: 35-41.

21 Selroos O, Pietinalho A, Lofroos AB, Riska H: Effects of early vs late intervention with inhaled corticosteroids in asthma. Chest 1995; 108:1228-1234.

22 Agertoft L, Pedersen S: Effects of long-term treatment with an inhaled corticosteroid on growth and pulmonary function in asthmatic children. Respir Med 1994;88:373-381. 